Check for updates

Cite this: RSC Adv., 2018, 8, 41986

Received 31st October 2018

Accepted 4th December 2018

DOI: $10.1039 / c 8 r a 09012 b$

rsc.li/rsc-advances

\section{Fast adsorption of methylene blue, basic fuchsin, and malachite green by a novel sulfonic-grafted triptycene-based porous organic polymer $\dagger$}

\author{
Cheng Li, ${ }^{a}$ Yan He, ${ }^{\text {ab }}$ Li Zhou, ${ }^{a}$ Ting Xu, ${ }^{a}$ Jun Hu, iD a Changjun Peng (D) *a \\ and Honglai Liu ${ }^{a}$
}

In this study, a novel triptycene-based porous polymer grafted with sulfonic acid (TPP- $\mathrm{SO}_{3} \mathrm{H}$ ) was successfully synthesized by the post-synthetic modification of the non-functionalized polymer TPP. The polymer TPP- $\mathrm{SO}_{3} \mathrm{H}$ was well-characterized and was found to be a fast and effective absorbent for the cationic dyes methylene blue (MEB), basic fuchsin (BF), and malachite green (MG), with over 95\% removal being observed within $10 \mathrm{~min}$ from initial concentrations of $100 \mathrm{mg} \mathrm{L}^{-1}, 100 \mathrm{mg} \mathrm{L}^{-1}$, and $300 \mathrm{mg} \mathrm{L}^{-1}$, respectively. The adsorption process for $M E B, B F$, and $M G$ was $p H$-dependent. The adsorption behaviours for MEB, BF, and MG follow pseudo-second-order kinetics and fit the Langmuir model. Moreover, the maximum adsorption capacities of $M E B, B F$, and $M G$ at room temperature were $981.8 \mathrm{mg} \mathrm{g}^{-1}, 586.2 \mathrm{mg} \mathrm{g}^{-1}$, and $1942.5 \mathrm{mg} \mathrm{g}^{-1}$, respectively. It is worth noting that the values of the MEB, BF, and MG adsorption capacities on $\mathrm{TPP}-\mathrm{SO}_{3} \mathrm{H}$ were 5.5, 3, and 1.8 times that of the nonfunctionalized polymer TPP based on the same adsorbent weight. It is suggested that (i) there are strong electrostatic attractions between the sulfonic groups of the TPP- $\mathrm{SO}_{3} \mathrm{H}$ and cationic dyes and (ii) the higher surface area and good porosity may contribute to the high dye adsorption capacity. Furthermore, TPP $-\mathrm{SO}_{3} \mathrm{H}$ exhibited good cyclic stability, which can be regenerated at least five times without a significant loss of adsorption capacity. Therefore, the facile strategy synthesis, as well as the excellent adsorption capacity and reusability, make polymer $\mathrm{TPP}-\mathrm{SO}_{3} \mathrm{H}$ an attractive adsorbent for wastewater treatment.

\section{Introduction}

With the development of industry, water pollution from organic dyes has become a serious issue due to its potential toxicity to humans and the natural environment. ${ }^{\mathbf{1}, 2}$ To reduce harm to the ecological environment and human health, it is important to search for an effective, convenient, and fast method to deal with wastewater. Presently, there are a large number of technologies that have been adopted for this purpose, including physical, chemical, biological, and adsorption. ${ }^{3,4}$ Among these methods, adsorption has attracted considerable attention owing to its highly efficient, easy-operation, low-cost, and recyclability. ${ }^{5}$ The key to adsorption technology is to choose efficient adsorbents. Of these adsorbents, many traditional porous materials, such as

${ }^{a}$ Key Laboratory for Advanced Materials and Department of Chemistry, East China University of Science and Technology, Shanghai 200237, China. E-mail: cjpeng@ ecust.edu.cn

biangxi Province Key Laboratory of Polymer Micro/Nano Manufacturing and Devices, School of Chemistry, Biology and Materials Science, East China University of Technology, Nanchang, 330013, People's Republic of China. E-mail: yanhe@ecit.cn $\uparrow$ Electronic supplementary information (ESI) available. See DOI: 10.1039/c8ra09012b activated carbon, ${ }^{6}$ zeolites, ${ }^{7}$ and oriented clay films, ${ }^{8}$ have been extensively studied. However, these materials have disadvantages of low adsorption capacities and long adsorption times. To overcome these problems, exploring novel porous adsorbents for efficient adsorption and the removal of dyes is still of great significance and a technical challenge.

Triptycene and its derivatives with $D_{3 \mathrm{~h}}$ symmetry and a threedimensional $(3 \mathrm{D})$ rigid structure are widely applied in supramolecular chemistry and materials science fields and are already in use in the synthesis of porous organic polymers., ${ }^{\mathbf{9}, 10}$ Compared to conventional adsorbents, the obvious features of triptycene-based porous materials are high surface areas, good porosities, and high thermal stability. Thus, triptycene-based polymers as adsorbents have a distinct advantage in adsorption-related fields, including the storage of hydrogen, uptake and selectivity of $\mathrm{CO}_{2}$, and adsorption of organic solvents and dyes. ${ }^{11-13}$ In addition, in our previous research, we successfully synthesized an alkyl-substituted amino functionalized triptycene-based 3D rigid polymer network via the postsynthetic modification method. The resulting compound had a high surface area and good $\mathrm{CO}_{2}$ adsorption capacity. ${ }^{14}$

Except for the amine group, some other active groups, such as sulfonic, hydroxyl, and carboxyl groups, have been grafted to 
organic or inorganic porous solids by the post-synthetic modification method. ${ }^{15-17}$ Among these groups, sulfonic acid groups have the following advantages: (1) they are hydrophilic, making it easy to wet a solid surface with water, ${ }^{18}(2)$ they are sufficiently easily ionized that the surface is negatively charged, facilitating the adsorption of cations, ${ }^{\mathbf{1 9}}$ and (3) the three oxygen atoms of the sulfonic acid group are preferred hydrogen bond acceptors and have a strong ability to form hydrogen bonds. ${ }^{20,21}$ All of these advantages greatly enhance the adsorption of cationic dyes. Recently, it has been reported that the grafting of sulfonic acid groups on the resin and MOF has been used for cationic dye adsorption, but the adsorption capacities of BF, MEB, and MG is only $127.0 \mathrm{mg} \mathrm{g}^{-1}, 351 \mathrm{mg} \mathrm{g}^{-1}$, and $596 \mathrm{mg} \mathrm{g}^{-1}$, respectively, and the adsorption time is long, owing to the low surface area or low adsorption sites. ${ }^{22,23}$ Thus, a highly porous polymer network with sulfonic acid functionality should be an excellent adsorbent for scavenging and removing cationic dyes, as it has a high surface area and a high density of dye adsorption active sites. However, the application of sulfonic acid porous organic polymer for organic dye removal has rarely been reported.

In this report, we describe the successful work of creating a sulfonic functionalized triptycene-based porous polymer TPP$\mathrm{SO}_{3} \mathrm{H}$ as a new adsorbent for the fast adsorption of cationic dyes, including MEB, BF, and MG. The adsorption kinetics, adsorption isotherms, effect of $\mathrm{pH}$ and regeneration of the adsorbent for the removal $\mathrm{MEB}, \mathrm{BF}$, and $\mathrm{MG}$ from an aqueous solution of $\mathrm{TPP}-\mathrm{SO}_{3} \mathrm{H}$ were studied in detail. In addition, the interaction between $\mathrm{TPP}-\mathrm{SO}_{3} \mathrm{H}$ and cationic dyes was analysed by quantitative calculations and desorption experiments.

\section{Experimental}

\section{Reagents and materials}

All of the purchased chemicals were of at least reagent grade and were used without further purification. Triptycene (98.0\%), anhydrous ferric chloride $\left(\mathrm{FeCl}_{3}, \geq 98.0 \%\right)$, 1,2-dichloroethane (DCE, 99.8\%), formaldehyde dimethyl acetal (FDA, $\geq 98.0 \%$ ), and chlorosulfonic acid $\left(\mathrm{ClSO}_{3} \mathrm{H}, 99 \%\right)$ were purchased from Sigma-Aldrich. All of the other solvents were purchased from TCI America. The methylene blue (MEB, 99\%), basic fuchsin (BF, 98\%), and malachite green (MG, 98\%), were purchased from Macklin Biochemical Co. Ltd. (Shanghai, China), and the above three dyes were used without further purification. Their structures are shown in Fig. 1.

\section{Synthesis of triptycene-based porous polymer (TPP)}

TPP was synthesized according to previous work. ${ }^{11}$ As shown in Scheme 1a, triptycene monomer (1.1054 g, $4.35 \mathrm{mmol})$ was dissolved in $20 \mathrm{~mL}$ of anhydrous DCE. To this solution, formaldehyde dimethyl acetal (FDA, $17.4 \mathrm{mmol}$ ) and anhydrous $\mathrm{FeCl}_{3}$ (17.4 mmol, $2.82 \mathrm{~g}$ ) were added in a nitrogen environment. The reaction mixture was magnetically stirred and heated to $80{ }^{\circ} \mathrm{C}$ for $24 \mathrm{~h}$. After cooling to room temperature, the crude product was collected via filtration and repeatedly washed with methanol until the filtrate was nearly colourless. The product

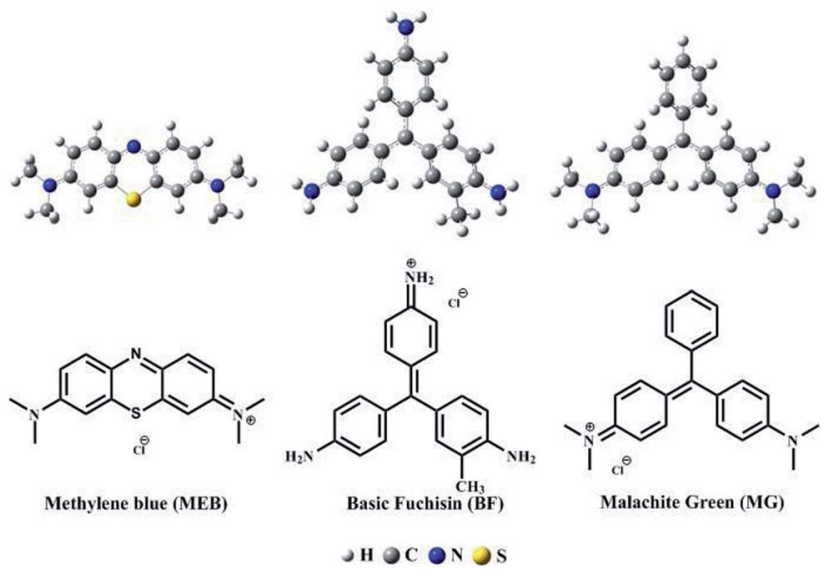

Fig. 1 Structures of the organic dyes MEB, BF and MG.

was further purified via Soxhlet extraction in methanol for $24 \mathrm{~h}$. Finally, the product was dried at $120{ }^{\circ} \mathrm{C}$ under vacuum to yield a yellow solid TPP with a good yield.

\section{Synthesis of sulfonic-grafted triptycene-based porous polymer (TPP-SO $3 \mathrm{H})$}

As shown in Scheme 1b, chlorosulfonic acid (1.0 mL, $15 \mathrm{mmol})$ was added dropwise to an ice-bath-cooled mixtures of TPP (125 $\mathrm{mg})$ in dichloromethane $(10 \mathrm{~mL})$. The resulting solution was stirred at room temperature for three days. Then, the solid was collected after the obtained mixtures were poured into ice. Afterwards, the product was washed liberally with water and dried to produce a brown $\mathrm{TPP}-\mathrm{SO}_{3} \mathrm{H}$ powder.

\section{Instruments and characterization}

The solid-state ${ }^{13} \mathrm{C}$ NMR spectra were recorded on a Bruker AVIII $500 \mathrm{MHz}$ spectrometer. The morphology of the samples
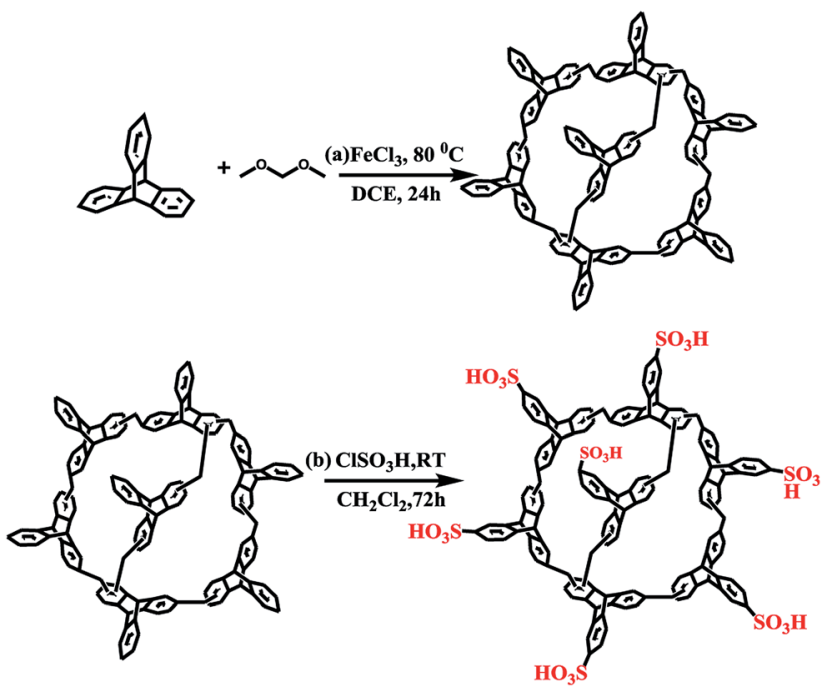

Scheme 1 (a) Simple synthesis of triptycene-based porous organic polymer and (b) schematic representation of the synthesis of the sulfonic functionalized polymer TPP- $\mathrm{SO}_{3} \mathrm{H}$. 
was characterized using a Nova NanoS 450 field emission scanning electron microscope (FE-SEM). High-resolution transmission electron microscope (HRTEM) images were recorded on a JEM-2100 transmission electron microscope. The powder samples were treated in ethanol using ultrasound for $20 \mathrm{~min}$ and then dropped and dried on carbon-coated copper grids. The powder X-ray diffraction (XRD) data were collected on a D/Max2550 VB/PC diffractometer (40 kV, $200 \mathrm{~mA})$ using a $\mathrm{Cu}$ $\mathrm{K} \alpha$ as the radiation. The $\mathrm{N}_{2}$ adsorption-desorption isotherms were measured at $77 \mathrm{~K}$ using a volumetric adsorption analyser (Micromeritics ASAP 2020). Before taking the adsorption measurements, the samples were degassed at $100{ }^{\circ} \mathrm{C}$ for $24 \mathrm{~h}$. The specific surface areas were calculated using the BrunauerEmmett-Teller (BET) and Langmuir methods. The total volume was calculated at $p / p_{0}=0.99$. The micropore volume was derived from the $t$-plot method. The UV-visible (UV-vis) spectra of the dye solutions were recorded using a UV-2550 spectrophotometer. The X-ray photoelectron spectroscopy (XPS) spectra were obtained with a Thermo ESCALAB 250XI multifunctional imaging electron spectrometer using $1486.6 \mathrm{eV} \mathrm{Al-K} \alpha$ radiation. The thermogravimetric analysis (TGA) was performed using a NetzschSta 449c thermal analyser system at a heating rate of $10{ }^{\circ} \mathrm{C}$ min in a $\mathrm{N}_{2}$ atmosphere. The Fourier Transform Infrared (FTIR) spectra were determined using a Nicolet iS10 FTIR spectrometer using the $\mathrm{KBr}$ pellet technique.

\section{Adsorption test}

\section{Organic dyes adsorption ${ }^{24}$}

Three organic pollutants, MEB, BF, and MG, were used to study the adsorption performance of TPP- $\mathrm{SO}_{3} \mathrm{H}$. In a typical MEB adsorption experiment, $2.5 \mathrm{mg}$ of TPP-SO ${ }_{3} \mathrm{H}$ were added to $5 \mathrm{~mL}$ of MEB aqueous solution while being mechanically shaken at room temperature. After adsorption for $24 \mathrm{~h}$, the mixture was filtered with a $0.22 \mu \mathrm{m}$ Millipore hydrophobic PTFE membrane, and the filtrate was measured using UV-vis spectroscopy. The best adsorption wavelengths of the MEB, BF, and MG are $664 \mathrm{~nm}, 543 \mathrm{~nm}$, and $618 \mathrm{~nm}$, respectively. The initial MEB concentration varied from 10 to $1200 \mathrm{mg} \mathrm{L}^{-1}$. Adsorption of the other two dyes on TPP-SO $\mathrm{S}_{3} \mathrm{H}$ was performed using solution concentrations of 10 to $2000 \mathrm{mg} \mathrm{L}^{-1}$ for $\mathrm{BF}$, and 10 to $3000 \mathrm{mg} \mathrm{L}^{-1}$ for MG. The MEB, BF, and MG solution concentrations from 1 to $1000 \mathrm{mg} \mathrm{L}^{-1}$ were employed for the adsorption study on TPP.

Organic dye adsorption kinetics. A volume of $2.5 \mathrm{mg}$ of porous polymer $\mathrm{TPP}-\mathrm{SO}_{3} \mathrm{H}$ was added to $5 \mathrm{~mL}$ of $\mathrm{MEB}, \mathrm{BF}$, and MG solution with initial concentrations of $100 \mathrm{mg} \mathrm{L}^{-1}$, $100 \mathrm{mg} \mathrm{L}^{-1}$, and $300 \mathrm{mg} \mathrm{L}^{-1}$ under mechanical shaking at room temperature. After adsorption for a predetermined time (from $1 \mathrm{~min}$ to $540 \mathrm{~min}$ ), the mixture was filtered with a $0.22 \mu \mathrm{m}$ Millipore hydrophobic PTFE membrane, and the filtrate was measured using UV-vis spectroscopy.

\section{pH effect}

The effect of $\mathrm{pH}$ on pollutant extraction was studied using different $\mathrm{pH}$ conditions, where the $\mathrm{pH}$ was adjusted by adding either $0.01 \mathrm{M} \mathrm{HCl}$ or $0.01 \mathrm{M} \mathrm{NaOH}$ solution. Then, $2.5 \mathrm{mg}$ of the porous polymer TPP-SO $\mathrm{S}_{3} \mathrm{H}$ were added to $5 \mathrm{~mL}$ of $300 \mathrm{mg} \mathrm{L}^{-1}$ $\mathrm{MEB}, 200 \mathrm{mg} \mathrm{L}^{-1} \mathrm{BF}$, and $800 \mathrm{mg} \mathrm{L}^{-1} \mathrm{MG}^{-}$solutions with different $\mathrm{pH}$ values at room temperature.

\section{Desorption experiments and reusability of $\mathrm{TPP}^{-\mathrm{SO}_{3} \mathrm{H}}$}

The adsorption/desorption cycles were conducted as follows. Each adsorption experiment consisted of $50 \mathrm{mg}$ of $\mathrm{TPP}_{-} \mathrm{SO}_{3} \mathrm{H}$ with $100 \mathrm{~mL}$ of $100 \mathrm{mg} \mathrm{L}^{-1}$ MEB, $100 \mathrm{mg} \mathrm{L}^{-1} \mathrm{BF}$, and $300 \mathrm{mg} \mathrm{L}^{-1}$ MG solutions for $12 \mathrm{~h}$. After the adsorption experiments, the regeneration adsorbent was then filtered and separated from the solution and washed with $0.1 \mathrm{M} \mathrm{HCl} /$ ethanol $(10: 90, \mathrm{v} / \mathrm{v})$, and the regeneration adsorbent was dried at $80^{\circ} \mathrm{C}$ under vacuum. This cycle was repeated five times.

\section{Uptake calculations}

(1) The calculation of the adsorption capacities and removal percentages can be expressed as: ${ }^{25}$

$$
\begin{aligned}
q_{t} & =\frac{\left(C_{0}-C_{t}\right) \times V}{m} \\
q_{\mathrm{eq}} & =\frac{\left(C_{0}-C_{\mathrm{eq}}\right) \times V}{m} \\
R \% & =\frac{\left(C_{0}-C_{\mathrm{e}}\right)}{C_{0}} \times 100 \%
\end{aligned}
$$

where $q_{t}\left(\mathrm{mg} \mathrm{g}^{-1}\right), R$, and $\mathrm{q}_{\mathrm{eq}}\left(\mathrm{mg} \mathrm{g}^{-1}\right)$ represent the uptake amount at a time $t(\mathrm{~min})$, removal percentages of the dyes and the equilibrium state, respectively, $C_{0}, C_{t}$, and $C_{\text {eq }}\left(\mathrm{mg} \mathrm{L}^{-1}\right)$ denote the concentrations of the dye solution at the initial, time $t$ (min) and equilibrium state, and $V(\mathrm{~L})$ and $m(\mathrm{~g})$ indicate the volume of the dye solution and mass of the adsorbent.

(2) Isotherm calculations.

The adsorption isotherms were fitted using the Langmuir and Freundlich models, respectively. The linear form of the Langmuir isotherm and Freundlich isotherm models can be expressed as: ${ }^{26,27}$

$$
\begin{aligned}
\frac{C_{\mathrm{eq}}}{q_{\mathrm{eq}}} & =\frac{1}{K_{\mathrm{L}} q_{\mathrm{max}}}+\frac{C_{\mathrm{eq}}}{q_{\mathrm{max}}} \\
\ln q_{\mathrm{eq}} & =\ln K_{\mathrm{F}}+\frac{1}{n_{\mathrm{F}}} \ln C_{\mathrm{eq}}
\end{aligned}
$$

where $q_{\mathrm{eq}}\left(\mathrm{mg} \mathrm{g}^{-1}\right)$ is the equilibrium adsorption capacity, $C_{\mathrm{eq}}$ $\left(\mathrm{mg} \mathrm{L}^{-1}\right)$ is the equilibrium dye concentration, $q_{\max }\left(\mathrm{mg} \mathrm{g}^{-1}\right)$ is maximum adsorption capacity, and $K_{\mathrm{L}}$ is the Langmuir constant. Therefore, the maximum adsorption amount $q_{\text {max }}$ can be obtained from the reciprocal of the slope of the plot of $C_{\text {eq }} /$ $q_{\text {eq }}$ versus $C_{\text {eq }}$. In addition, $K_{\mathrm{F}}$ is the Freundlich constant (mg $\mathrm{g}^{-1}$ ) and $1 / n_{\mathrm{F}}$ is the heterogeneity factor.

(3) Calculation of the adsorption kinetics.

The kinetic parameters were fit using the pseudo-first-order and pseudo-second-order models, which can be described as: $:^{28,29}$ 


$$
\begin{gathered}
\ln \left(q_{\max }-q_{\mathrm{t}}\right)=\ln q_{\mathrm{eq}}+K_{1} t \\
\frac{t}{q_{t}}=\frac{1}{K_{2} q_{\mathrm{eq}}{ }^{2}}+\frac{t}{q_{\mathrm{eq}}}
\end{gathered}
$$

where $K_{1}$ and $K_{2}$ are the specific rate constants for the pseudofirst-order kinetic and pseudo-second-order kinetic models, respectively. For the first-order kinetic model, $k_{1}$ can be calculated from the intercept, and $q_{\text {eq }}$ could be calculated from the slope. For the second-order kinetic model, the equilibrium adsorption amount could be calculated from the slope, and $k_{2}$ could be calculated from the intercept and $q_{\text {eq }}$.

\section{Quantum calculations}

All of the molecules were fully optimized using the B3LYP ${ }^{30,31}$ method combined with the $6-311 \mathrm{G}(\mathrm{d})^{32}$ basis set for all the atoms involved. During the calculations, the same theoretical method and basis set were used for the frequency analysis to confirm that all the structures are real minimums on the potential energy surface. In addition, no symmetry constraint was performed. To simplify the complicated calculation process, we only selected a part of the TPP-SO ${ }_{3} \mathrm{H}$ for calculation. All the calculations were performed with the Gaussian 09 (ref. 33) software. Additionally, the electrostatic potential surface (ESP) and non-covalent interaction (NCI) analysis were performed by the Multiwfn programme and visualized using the VMD software.

\section{Results and discussion}

\section{Characterization of TPP-SO $\mathrm{S}_{3} \mathrm{H}$}

The morphology and crystalline nature of the synthesized TPP$\mathrm{SO}_{3} \mathrm{H}$ were investigated by FE-SEM, HRTEM, and XRD. As shown in Fig. 2a, the TPP-SO ${ }_{3} \mathrm{H}$ exhibits a cluster morphology of the submicrometer particles, which is not clearly changed compared with the morphology of pristine polymer TPP. ${ }^{11}$ The HRTEM image (Fig. 2b) shows that the TPP-SO ${ }_{3} \mathrm{H}$ possesses a large amount of amorphous microporosity. In addition, with a broad band from $10^{\circ}$ to $80^{\circ}$ in the XRD pattern (Fig. S1, ESI $\dagger$ ),
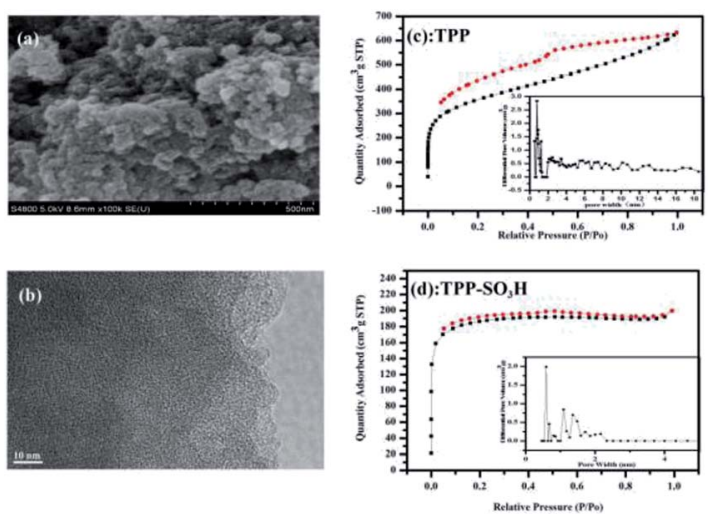

Fig. 2 (a) HR-TEM of TPP- $\mathrm{SO}_{3} \mathrm{H}$, (b) SEM of TPP- $\mathrm{SO}_{3} \mathrm{H}$, (c and d) $\mathrm{N}_{2}$ adsorption-desorption isotherms and pore size distributions (the inset of ( $\mathrm{c}$ and $\mathrm{d}$ )) of TPP and TPP-SO${ }_{3} \mathrm{H}$ at $77 \mathrm{~K}$. the results confirmed the amorphous nature of $\mathrm{TPP}-\mathrm{SO}_{3} \mathrm{H}$. Thermal gravimetric analysis (TGA) shows that the TPP- $\mathrm{SO}_{3} \mathrm{H}$ was relatively stable (Fig. S2, ESI $\dagger$ ). The initial small weight loss below $100{ }^{\circ} \mathrm{C}$ was mainly caused by the release of entrapped solvent or some small gaseous molecules in the micropores. The polymer TPP-SO $\mathrm{S}_{3} \mathrm{H}$ was stable to approximately $160{ }^{\circ} \mathrm{C}$ due to the decomposition of the functionalization sulfonic acid group. All of the obtained polymer TPP- $\mathrm{SO}_{3} \mathrm{H}$ was insoluble in dilute solutions of $\mathrm{NaOH}$ and $\mathrm{HCl}$, as well as common organic solvents, such as dichloromethane, acetone, methanol, THF and DMF, indicating the good chemical stability of the polymer. We note that the high physicochemical stability of the polymer is good enough for potential applications in organic dyes capture.

Nitrogen adsorption-desorption isotherms of the TPP (Fig. 2c) and TPP-SO $\mathrm{S}_{3} \mathrm{H}$ (Fig. 2d) were collected at $77 \mathrm{~K}$. Notably, the polymer TPP-SO $\mathrm{S}_{3} \mathrm{H}$ exhibited almost ideal type-I isotherms and a large desorption hysteresis disappeared after the modification of the TPP. The Brunauer-Emmett-Teller (BET) surface areas obtained from the experimental data were $1220.1 \mathrm{~m}^{2} \mathrm{~g}^{-1}$ and $573.3 \mathrm{~m}^{2} \mathrm{~g}^{-1}$ for TPP and TPP-SO $\mathrm{S}_{3} \mathrm{H}$, respectively. As expected, the surface area decreased upon functionalization modification. The pore size distributions (PSD) of the TPP (the inset of Fig. 2c) and TPP-SO $\mathrm{S}_{3} \mathrm{H}$ (the inset of Fig. 2d) were derived using the entire range of the $\mathrm{N}_{2}$ adsorption isotherms measured at $77 \mathrm{~K}$. Along with the decrease in surface area, the pore size became progressively smaller with aromatic sulfonation. The detailed porous properties of the polymers are summarized in Table S1.†

The functional groups on the surface of $\mathrm{TPP}-\mathrm{SO}_{3} \mathrm{H}$ were studied using FTIR spectrophotometry over a range from range of 4000 to $500 \mathrm{~cm}^{-1}$ (Fig. S3, ESI $\dagger$ ). The FTIR spectra of the polymer TPP underwent significant changes after sulfonation modification. The characteristic absorption peaks of the sulfonic acid groups appeared at $1032 \mathrm{~cm}^{-1}$, which are assigned to the symmetric stretching of the $\mathrm{S}=\mathrm{O}$ bond as a result of inducing the $\mathrm{SO}_{3} \mathrm{H}$ groups into the TPP and an absorption at $610 \mathrm{~cm}^{-1}$, which is due to the bending vibrations of $\mathrm{OH}$ groups hydrogen bonded to $\mathrm{SO}_{3} \mathrm{H}$ groups. ${ }^{34}$ In addition, an XPS survey spectrum of the TPP-SO $\mathrm{S}_{3} \mathrm{H}$ was performed (Fig. S4a, $\mathrm{ESI} \dagger$ ), which shows peaks corresponding to $\mathrm{C}, \mathrm{O}$, and $\mathrm{S}$. This is different from the XPS survey spectrum of the TPP, where only peaks assignable to $\mathrm{C}$ and $\mathrm{O}$ are observed, suggesting that the sulfur containing groups were introduced into the TPP through the sulfonation modification. The presence of sulfur in the TPP$\mathrm{SO}_{3} \mathrm{H}$ could be further demonstrated by the high-resolution $\mathrm{S} 2 \mathrm{p}$ spectrum (Fig. S4b, ESI $\dagger$ ), which exhibits a single peak at $168.3 \mathrm{eV}$, indicating that the sulfur is in the form of sulfonic acid. ${ }^{35,36}$ These results clearly demonstrate that the sulfonic acid group was successfully modified on the surface of the TPP.

The molecular structure of the TPP- $\mathrm{SO}_{3} \mathrm{H}$ was further investigated by ${ }^{13} \mathrm{C}$ NMR (Fig. S5, ESI $\dagger$ ). The peaks at 90-120 ppm are assigned to the carbon atoms in the aromatic systems. The peak at $134 \mathrm{ppm}$ corresponds to the carbon atoms of the substituted aromatic ring. Additionally, the peak at $33.84 \mathrm{ppm}$ indicates the methylene carbon formed by the Friedele-Crafts alkylation reaction. The presences of $-\mathrm{OCH}_{2}(49.98 \mathrm{ppm})$ resonances 
indicate secondary reaction channels involving FDA during the polymerization. ${ }^{37}$

\section{Adsorption kinetics of $\mathrm{MEB}, \mathrm{BF}$, and $\mathrm{MG}$ on $\mathrm{TPP}_{-} \mathrm{SO}_{3} \mathrm{H}$}

The time-dependent adsorption of MEB, MG, and BF on TPP$\mathrm{SO}_{3} \mathrm{H}$ was investigated at initial concentrations of $100 \mathrm{mg} \mathrm{L}^{-1}, 100 \mathrm{mg} \mathrm{L}^{-1}$, and $300 \mathrm{mg} \mathrm{L}^{-1}$. Fig. 3a shows the adsorption kinetics curves for the three dyes. The removal rates were all very rapid during the initial stages of the adsorption process. After a very rapid adsorption, the uptake rates slowly declined with time and reached equilibrium values at approximately $10 \mathrm{~min}$ for all the three dyes, which was faster than for some other materials. ${ }^{38,39}$ The equilibrium adsorption rates constant $\left(K_{2}\right)$ of the MEB, BF, and MG were $0.0026,0.0149$ and $0.0093 \mathrm{~g} \mathrm{mg}^{-1} \mathrm{~min}^{-1}$, respectively, those $K_{2}$ value were larger than those previously reported porous adsorbents for the three dyes are listed in Table S2. $\uparrow$ The high initial uptake rate and the short adsorption equilibrium time demonstrated that the surfaces of the polymer TPP- $\mathrm{SO}_{3} \mathrm{H}$ had a high density of active sites for dyes adsorption. Hence, a practical advantage of using the sulfonic acid polymer TPP$\mathrm{SO}_{3} \mathrm{H}$ as an adsorbent would be its ability to remove more dyes in a considerably shorter adsorption time. However, to analyse the adsorption kinetics of $\mathrm{TPP}-\mathrm{SO}_{3} \mathrm{H}$, the adsorption data were analysed using pseudo-first-order (Fig. S6, ESI $\dagger$ ) and pseudo-second-order kinetic models (Fig. 3b). The correlation coefficients obtained by fitting the pseudo-firstorder and pseudo-second-order kinetic models are listed in Table S3. $\dagger$ From the figures and the table, an extremely high correlation coefficient $\left(R^{2}>0.997\right)$ was obtained for the pseudo-second-order kinetic model, and the calculated dyes adsorption capacity and experimental values are very close. This indicates that the rate of adsorption of the TPP- $\mathrm{SO}_{3} \mathrm{H}$ adsorbent for the organic dyes MEB, BF, and MG depends on the available adsorption sites.

\section{Effect of $\mathrm{pH}$ on the adsorption of MEB, BF, and MG on TPP-} $\mathrm{SO}_{3} \mathrm{H}$

The adsorption of MEB, BF, and MG dyes from aqueous solution on TPP- $\mathrm{SO}_{3} \mathrm{H}$ is primarily influenced by the surface charge of the adsorbent and the degree of ionization of the adsorptive sites. The effect of the $\mathrm{pH}$ on the adsorption of $\mathrm{MEB}, \mathrm{BF}$, and MG was studied in the $\mathrm{pH}$ range of 2.0 to 9.0. As is well-known,
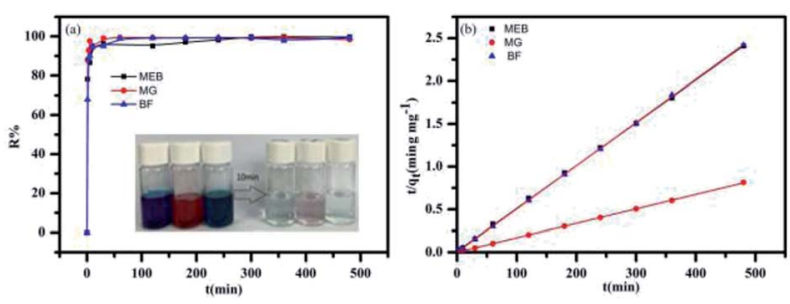

Fig. 3 (a) MEB, BF, and MG adsorption on the polymer TPP- $\mathrm{SO}_{3} \mathrm{H}$ at different times. (b) Plots of the pseudo-second-order kinetics for the adsorption of MEB, BF and MG (MEB and BF almost coincide).
$-\mathrm{SO}_{3} \mathrm{H}$ is strongly acid group with a large degree of ionization and is hardly unaffected by changes in the $\mathrm{pH}$ of the solution. ${ }^{\mathbf{4 0}}$ It could be claimed that only negatively charged adsorbent species exist in the whole examined $\mathrm{pH}$ solution range of 2-9 is stated with a predominant role of $\mathrm{SO}_{3}{ }^{-}$groups. The surface of TPP- $\mathrm{SO}_{3} \mathrm{H}$ is negatively charged whereas the dye molecules are positively charged. Thus, as it was expected taking into account possibility of electrostatic interactions between the cationic dyes and the sulfonic groups, the adsorption of $\mathrm{MEB}, \mathrm{BF}$, and MG on $\mathrm{TPP}_{-} \mathrm{SO}_{3} \mathrm{H}$ is $\mathrm{pH}$ independent. As seen in Fig. 4, the removal efficiency of the dye does not obviously change with the $\mathrm{pH}$ range 2.0 to 9.0 , and most of the dye wastewater is in this range. In fact, the acidic dyes wastewater is pre-treated with alkali before treatment. In addition, literature data report that pH does not influence on the dyes adsorption on the strongly acid cation exchanger. ${ }^{22}$

Although ion exchange is the most significant mechanism in $\mathrm{MEB}, \mathrm{BF}$, and MG removal via TPP-SO $\mathrm{S}_{3} \mathrm{H}$, some extent of pure physical adsorption may also occur. For example, $\pi-\pi$ stacking interactions between the aromatic rings of the cationic dye and the aromatics rings of TPP- $\mathrm{SO}_{3} \mathrm{H}$ can play a role in the adsorption of MEB, BF and MG. Furthermore, the high affinity of the dye for the TPP- $\mathrm{SO}_{3} \mathrm{H}$ may also result from the formation of $\mathrm{H}$ bonds.

To gain a deeper understanding of the adsorption mechanism of the MEB, BF, and MG dyes on TPP-SO ${ }_{3} \mathrm{H}$, we employed theoretical quantum calculations to analyse the interactions between the TPP-SO $\mathrm{S}_{3} \mathrm{H}$ and cationic dyes. The ESP surfaces (isosurfaces with an electron density $=0.001 \mathrm{au}$ ) with the most negative surface ESPs $\left(V_{\mathrm{s}, \mathrm{min}}\right)$ or the most positive surface ESPs $\left(V_{\mathrm{s}, \max }\right)$ are depicted in Fig. S7. $\uparrow$ The ESP surfaces for the MEB, $\mathrm{BF}$, and $\mathrm{MG}$ are shown in blue and have a $V_{\mathrm{s} \text {,max }}$ of $83.25 \mathrm{kcal} \mathrm{mol}^{-1}, 96.48 \mathrm{kcal} \mathrm{mol}^{-1}$, and $74.08 \mathrm{kcal} \mathrm{mol}^{-1}$, respectively. In contrast, the ESP of the TPP-SO ${ }_{3} \mathrm{H}$ is negative and shown in red, with a $V_{\mathrm{s}, \mathrm{min}}$ of $-37.35 \mathrm{kcal} \mathrm{mol}^{-1}$, suggesting that it is easy to adsorb cations. The ESP analysis confirms that TPP-SO ${ }_{3} \mathrm{H}$ will favourably adsorb MEB, BF, and MG via electrostatic interactions.

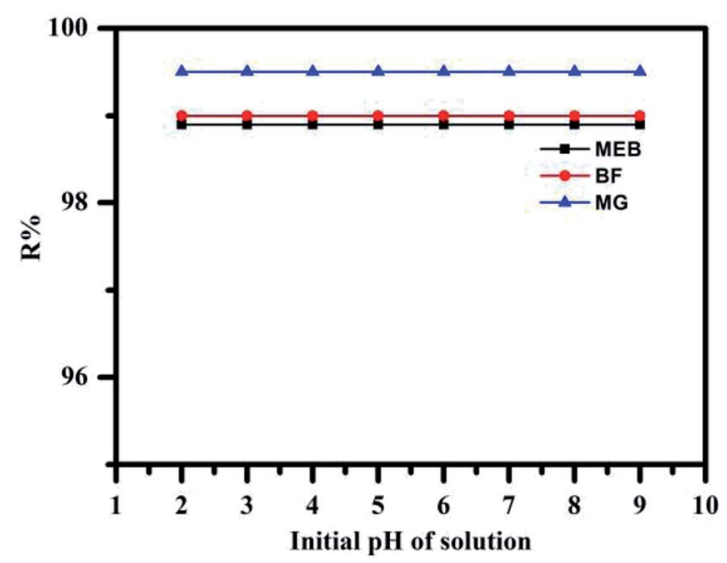

Fig. 4 Effect of pH on the adsorption of MEB (black), BF (red), and MG (blue) (concentration MEB: $300 \mathrm{mg} \mathrm{L}^{-1}$, BF concentration: $200 \mathrm{mg} \mathrm{L}^{-1}$, and MG concentration: $800 \mathrm{mg} \mathrm{L}^{-1}$ ). 
The optimized structures of the complexes are shown in (Fig. S8, ESI $\dagger$ ). It is known that if the distance between two atoms is less than the sum of the van der Waals radii of them (H: $1.2 \AA$, O: $1.52 \AA$ ), then the two atoms are bonded to each other. We show all the $\mathrm{O}-\mathrm{H}$ bonds (less than $2.72 \AA$ ) with red dashed lines. These $\mathrm{O}{ }^{\cdots} \mathrm{H}-\mathrm{C}$ bonds conform to the characteristics of hydrogen bonding. In addition, we further confirmed the existence of hydrogen bonds by NCI, where blue represents a strong attraction interaction, green represents a weak interaction, and red represents a repulsive interaction. As shown in Fig. 5, there is a distinct dark green isosurface between the $\mathrm{O}$ and $\mathrm{H}$ atoms (indicated by the red circle). Thus, there is a typical hydrogen bond between the polymer and the dye, which enhances the interaction between the polymer and the dye.

\section{Adsorption isotherms of the MEB, BF and MG on TPP and $\mathrm{TPP}_{-} \mathrm{SO}_{3} \mathrm{H}$}

Fig. 6a and c show plots of $C_{0}$ versus $q_{\mathrm{eq}}$ for dye adsorption at room temperature. The adsorption amounts of $\mathrm{MEB}, \mathrm{BF}$, and MG initially increase sharply with the dye concentration and begin to stabilize at high dye concentrations. The adsorption capacities of TPP-SO $\mathrm{S}_{3} \mathrm{H}$ are obviously higher than pristine TPP, showing that the sulfonic acid group has a positive effect on the adsorption isotherm. To quantitatively analyse the adsorption isotherm data, the Langmuir and Freundlich isotherm models ((eqn (4) and (5)) were used to describe the adsorption progress and to investigate the mechanisms of adsorption. The inspection of the linear Langmuir(Fig. 6b and d) and Freundlich isotherm plots (Fig. S9, ESI $\dagger$ ) suggests that the Langmuir model allows a much better analysis of data than the Freundlich model. The Langmuir parameters, as well as the regression coefficients $\left(R^{2}\right)$ are listed in Table S4. $\dagger$ The high correlation coefficients $\left(R^{2}\right)$ indicate that the Langmuir isotherm can explain the adsorption process. The maximum adsorption capacities of the MEB, BF and MG calculated by the Langmuir model were $983.4 \mathrm{mg} \mathrm{g}^{-1}, 588.2 \mathrm{mg} \mathrm{g}^{-1}$, and $1947.0 \mathrm{mg} \mathrm{g}^{-1}$, respectively. The adsorption capacities of the $\mathrm{TPP}-\mathrm{SO}_{3} \mathrm{H}$ with the previously reported porous adsorbents for the three dyes are listed in Table 1 . The TPP-SO ${ }_{3} \mathrm{H}$ exhibits a competitive adsorption capacity with respect to the other reported porous adsorbents.

\section{Desorption and regeneration of $\mathrm{TPP}-\mathrm{SO}_{3} \mathrm{H}$}

The regeneration and reuse of adsorbents is an important factor in commercial viability. First, the most common methods for the dye desorption, i.e., solutions of $0.1 \mathrm{M} \mathrm{HCl}$ and $0.1 \mathrm{M} \mathrm{NaOH}$, were used as the desorption solution. Unfortunately, no dyes
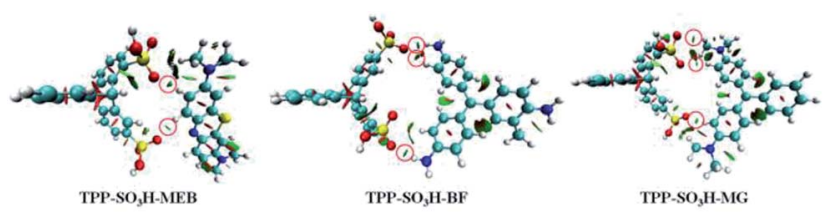

Fig. $5 \mathrm{NCl}$ isosurfaces of the three complexes.
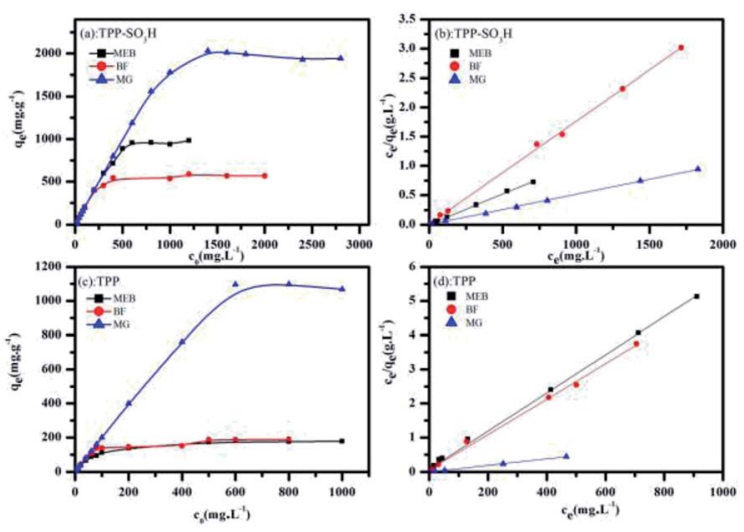

Fig. 6 ( $a$ and $b$ ) TPP- $\mathrm{SO}_{3} \mathrm{H}$ adsorption isotherms for the adsorption of MEB, BF and MG and the corresponding Langmuir; (c and d) TPP adsorption isotherms for the adsorption of MEB, BF and MG and the corresponding Langmuir.

could be desorbed. Considering that the dye binding with the TPP- $\mathrm{SO}_{3} \mathrm{H}$ may not be only via electrostatic interaction but also by other binding forces, such as hydrogen bonding, ethanol was also chosen for breaking these nonspecific binding interactions. Regeneration of the MEB, BF and MG-loaded TPP- $\mathrm{SO}_{3} \mathrm{H}$ by ethanol is completely unaffected, confirming that the strong electrostatic attraction between the dyes and the $\mathrm{TPP}-\mathrm{SO}_{3} \mathrm{H}$ is the predominant mechanism of adsorption. However, using an ethanol-water mixture with $0.1 \mathrm{M} \mathrm{HCl}$ shows a significant improvement in dye desorption performance, indicating that the dye is bound to the TPP- $\mathrm{SO}_{3} \mathrm{H}$ through more than one binding force, which has been proved by theoretical quantum calculations, the previous literature ${ }^{49}$ also demonstrated the existence of hydrogen bonds by similar desorption experiments. As shown in Fig. 7, when using $0.1 \mathrm{M} \mathrm{HCl} /$ ethanol $(10: 90, \mathrm{v} / \mathrm{v})$ as the eluent, the adsorption capacity of the TPP-SO ${ }_{3} \mathrm{H}$ adsorbent does not significantly change after five times reuse for the $\mathrm{MEB}, \mathrm{BF}$ and MG. The results indicate that the $\mathrm{TPP}-\mathrm{SO}_{3} \mathrm{H}$ has a remarkable potential for dye removal after five adsorptiondesorption cycles.

Table 1 Comparison of MEB, BF and MG adsorption among different adsorbents

$\underline{q_{\max }\left(\mathrm{mg} \mathrm{g}^{-1}\right) \text { of different dyes }}$

\begin{tabular}{|c|c|c|c|c|}
\hline Adsorbents & MEB & $\mathrm{BF}$ & MG & Ref. \\
\hline MOF-235 & 187 & - & - & 41 \\
\hline MOF-10- $\mathrm{SO}_{3} \mathrm{H}$ & 351 & - & 596 & 23 \\
\hline MIL-100(Fe) & - & - & 485 & 42 \\
\hline Modified biomass & 548.1 & 594 & - & 43 \\
\hline Breadnut core & 369 & - & - & 44 \\
\hline CEN & 110.8 & - & 77.6 & 45 \\
\hline Magnetic $\mathrm{NH}_{2}$-MIL-101 & - & - & 274 & 46 \\
\hline $\mathrm{Fe}_{3} \mathrm{O}_{4} / \mathrm{PCC}$ MNPs & 60.06 & - & 66.84 & 47 \\
\hline AGS & 212 & - & - & 48 \\
\hline TPP & 175.50 & 188.34 & 1095.29 & This work \\
\hline TPP-SO ${ }_{3} \mathrm{H}$ & 981.81 & 586.86 & 1942.50 & This work \\
\hline
\end{tabular}




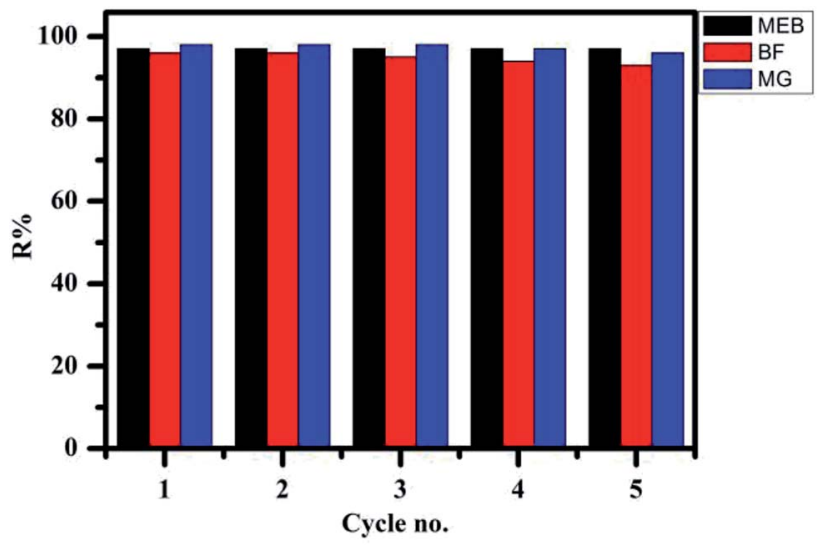

Fig. 7 Reusability of the polymer TPP- $\mathrm{SO}_{3} \mathrm{H}$ for removing MEB (Black), BF (Red) and MG (blue).

\section{Conclusions}

A triptycene-based porous polymer with sulfonic acid group (which are known as strong cation exchanger) was synthesized using a post-synthetic method and applied to remove MEB, BF and MG from an aqueous solution. The percentage uptake of the dyes is concentration-dependent and decreases as the dye concentration increases. The equilibrium adsorption behaviour of the MEB, BF, and MG on TPP-SO ${ }_{3} \mathrm{H}$ followed the Langmuir adsorption isotherm with theoretical maximum adsorption capacities of $983.4 \mathrm{mg} \mathrm{g}^{-1}, 588.2 \mathrm{mg} \mathrm{g}^{-1}$ and $1947.0 \mathrm{mg} \mathrm{g}^{-1}$, respectively. The negative surface charge, higher surface area and good porosity resulted in a very high maximum adsorption capacity for the MEB, BF, and MG.

The reversibility of the adsorption depends on if the predominant mechanism is a strong binding, such as ionic bonding or H-bonding, which can be confirmed by quantum calculations and desorption studies. The results indicate that the strong cation exchange (electrostatic attractions) between the sulfonic acid group of the TPP- $\mathrm{SO}_{3} \mathrm{H}$ and cationic dyes is proposed as the main adsorption mechanism.

Importantly, the TPP-SO $\mathrm{S}_{3} \mathrm{H}$ could be reused up to five cycles without any severe loss of MEB, BF, and MG adsorption capacity. The ease of synthesis and low cost in combination with the efficient and rapid adsorption properties make TPP$\mathrm{SO}_{3} \mathrm{H}$ an attractive adsorbent for a wide range of large-scale applications in the water purification and treatment fields.

\section{Conflicts of interest}

There are no conflicts to declare.

\section{Acknowledgements}

This work is supported by National Key Basic Research Program of China (2015CB251401) and the National Natural Science Foundation of China (No. 21476070, 21776069).

\section{References}

1 P. C. Vandevivere, R. Bianchi and W. Verstraete, J. Chem. Technol. Biotechnol., 1998, 72, 289-302.

2 V. Geissen, H. Mol, E. Klump, G. Umlauf, M. Nadale, M. van der Ploega, S. E. A. T. M. van de Zee and C. J. Ritsem, International Soil and Water Conservation Research, 2015, 3, $57-65$.

3 I. Ali, Chem. Rev., 2012, 112, 5073-5091.

4 G. Crini, Bioresour. Technol., 2006, 97, 1061-1085.

5 E. Worch, Adsorption Technology in Water Treatment: Fundamentals, Processes, and Modeling, Walter de Gruyter, 2012.

6 D. Mohan, K. P. Singh and V. K. Singh, J. Hazard. Mater., 2008, 152, 1045-1053.

7 E. Alver and A. Ü. Metin, Chem. Eng. J., 2012, 200-202, 59-67. 8 Y. Zhou, Y. Wang, T. F. Liu, G. Xu, G. G. Chen, H. Y. Li, Q. Q. Zhuo, J. X. Zhang and C. Yan, Sci. Rep., 2017, 7, 45065.

9 B. S. Ghanem, K. J. Msayib, N. B. McKeown, K. D. M. Harris, Z. G. Pan, P. M. Budd, A. Butler, J. Selbie and D. Book, Chem. Commun., 2007, 67-69.

10 B. S. Ghanem, M. Hashem, K. D. M. Harris, K. J. Msayib, M. Xu, P. M. Budd, N. Chaukura, D. Book, S. Tedds, A. Walton and N. B. McKeown, Macromolecules, 2010, 43, 5287-5294.

11 C. Zhang, P. C. Zhu, L. Tan, J. M. Liu, B. Tan, X. L. Yang and H. B. Xu, Macromolecules, 2015, 48, 8509-8514.

12 M. Suyetin, Int. J. Hydrogen Energy, 2017, 42, 3114-3121.

13 R. Bera, M. Ansari, S. Mondal and N. Das, Eur. Polym. J., 2018, 99, 259-267.

14 Y. He, X. Zhu, Y. Li, C. Peng, J. Hu and H. Liu, Microporous Mesoporous Mater., 2015, 214, 181-187.

15 L. Jin, W. Li, Q. Xu and Q. Sun, Cellulose, 2015, 22, 24432456.

16 B. Li, F. Su, H. K. Luo, L. Liang and B. Tan, Microporous Mesoporous Mater., 2011, 138, 207-214.

17 A. C. Chao, S. S. Shyu, Y. C. Lin and F. L. Mi, Bioresour. Technol., 2004, 91, 157-162.

18 D. S. Kim, H. B. Park, Y. M. Lee, Y. H. Park and J. Rhim, J. Appl. Polym. Sci., 2004, 93, 209-218.

19 A. C. G. Hotze, H. Kooijman, A. L. Spek, J. G. Haasnoot and J. Reedijk, New J. Chem., 2004, 28, 565-569.

20 M. S. Weiss, M. Brandl, J. Sühnel, D. Pal and R. Hilgenfeld, Trends Biochem. Sci., 2001, 26, 521-523.

21 T. Steiner and W. Saenger, Acta Crystallogr., Sect. D: Biol. Crystallogr., 1993, 49, 592-593.

22 G. Bayramoglu, B. Altintas and M. Y. Arica, Chem. Eng. J., 2009, 152, 339-346.

23 X. P. Luo, S. Y. Fu, Y. M. Du, J. Z. Guo and B. Li, Microporous Mesoporous Mater., 2017, 237, 268-274.

24 Q. Li, J. Zhang, Q. Lu, J. Lu, J. Li, C. Dong and Q. Zhu, Mater. Lett., 2016, 170, 167-170.

25 F. Renault, N. Morin-Crini, F. Gimbert, P. M. Badot and G. Crini, Bioresour. Technol., 2008, 99, 7573-7586.

26 K. K. Panday, G. Prasad and V. N. Singh, Water Res., 1985, 19, 869-873. 
27 Y. S. Ho, D. A. J. Wase and C. F. Forster, Environ. Technol., 1996, 17, 71-77.

28 Y. S. Ho and G. McKay, Chem. Eng. J., 1998, 70, 115-124.

29 J. P. Simonin, Chem. Eng. J., 2016, 300, 254-263.

30 A. D. Becke, Phys. Rev. A, 1988, 38, 3098.

31 C. Lee, W. Yang and R. G. Parr, Phys. Rev. B, 1988, 37, 785.

32 P. C. Hariharan and J. A. Pople, Theor. Chim. Acta, 1973, 28, 213-222.

33 M. J. Frisch, G. W. Trucks, H. B. Schlegel, G. E. Scuseria, M. A. Robb, J. R. Cheeseman, G. Scalmani, V. Barone, B. Mennucci, G. A. Petersson, H. Nakatsuji, M. Caricato, X. Li, H. P. Hratchian, A. F. Izmaylov, J. Bloino, G. Zheng, J. L. Sonnenberg, M. Hada, M. Ehara, K. Toyota, R. Fukuda, J. Hasegawa, M. Ishida, T. Nakajima, Y. Honda, O. Kitao, H. Nakai, T. Vreven, J. A. Montgomery Jr, J. E. Peralta, F. Ogliaro, M. Bearpark, J. J. Heyd, E. Brothers, K. N. Kudin, V. N. Staroverov, R. Kobayashi, J. Normand, K. Raghavachari, A. Rendell, J. C. Burant, S. S. Iyengar, J. Tomasi, M. Cossi, N. Rega, J. M. Millam, M. Klene, J. E. Knox, J. B. Cross, V. Bakken, C. Adamo, J. Jaramillo, R. Gomperts, R. E. Stratmann, O. Yazyev, A. J. Austin, R. Cammi, C. Pomelli, J. W. Ochterski, R. L. Martin, K. Morokuma, V. G. Zakrzewski, G. A. Voth, P. Salvador, J. J. Dannenberg, S. Dapprich, A. D. Daniels, O. Farkas, J. B. Foresman, J. V. Ortiz, J. Cioslowski and D. J. Fox, Gaussian 09, Revision A, Gaussian, Inc., Wallingford CT, 2009.

34 W. Zhou, M. Yoshino, H. Kita and K. Okamoto, Ind. Eng. Chem. Res., 2001, 40, 4801-4807.
35 H. C. Chien, L. D. Tsai, C. P. Huang, C. Kang, J. N. Lin and F. C. Chang, Int. J. Hydrogen Energy, 2013, 38, 13792-13801. 36 H. Zarrin, D. Higgins, Y. Jun, Z. Chen and M. Fowler, J. Phys. Chem. C, 2011, 115, 20774-20781.

37 B. Li, R. Gong, W. Wang, X. Huang, W. Zhang, H. Li, C. Hu and B. Tan, Macromolecules, 2011, 44, 2410-2414.

38 K. Zarrini, A. A. Rahimi, F. Alihosseini and H. Fashandi, J. Cleaner Prod., 2017, 142, 3645-3654.

39 W. Stawiński, A. Węgrzyn, O. Freitas, L. Chmielarz and S. Figueiredo, Microporous Mesoporous Mater., 2017, 250, 72-87.

40 S. Durmaz and O. Okay, Polymer, 2000, 41, 3693-3704.

41 E. Haque, J. W. Jun and S. H. Jhung, J. Hazard. Mater., 2011, 185, 507-511.

42 S. H. Huo and X. P. Yan, J. Mater. Chem., 2012, 22, 74497455.

43 J. X. Yu, B. H. Li, X. M. Sun, J. Yuan and R. Chi, J. Hazard. Mater., 2009, 168(2-3), 1147-1154.

44 L. B. L. Lim, N. Priyantha, C. H. Ing, M. K. Dahri, D. T. B. Tennakoon, T. Zehra and M. Suklueng, Desalin. Water Treat., 2015, 53, 964-975.

45 M. K. Dahri, M. R. R. Kooh and L. B. L. Lim, Alexandria Eng. J., 2015, 54, 1253-1263.

46 H. Liu, L. Chen and J. Ding, RSC Adv., 2016, 6, 48884-48895. 47 Y. Hua, J. Xiao, Q. Zhang, C. Cui and C. Wang, Nanoscale Res. Lett., 2018, 13, 99.

48 F. Liu, S. Teng, R. Song and S. Wang, Desalination, 2010, 263, 11-17.

49 M. Greluk and Z. Hubicki, Desalination, 2011, 278, 219-226. 